\title{
A gestão democrática da educação em tempos de parceria entre o público e o privado
}

Vera Maria Vidal Peroni ${ }^{*}$

Resumo: O objetivo deste artigo é analisar a relação público/privado e suas consequências para a gestão democrática da educação. Apresenta o contexto atual, pois entende a inserção da lógica privada nas escolas públicas como parte de mudanças ocorridas, neste período particular do capitalismo, que redefinem o papel do Estado e as políticas sociais. Em termos gerais, concluiu-se que as relaçóes entre o público e o privado se manifestam, no período atual, tanto no que se refere à alteração da propriedade quanto em relação ao que permanece na propriedade estatal, além de reorganizarem os processos educacionais na lógica do mercado.

Palavras-chave: Terceira Via; parceria público/privado na educação; políticas educacionais; gestão democrática.

Democratic management of education in times of public-private partnership

The aim of this article is to analyze the public-private relationship and its consequences for the democratic management of education. It presents the current scenario, as it sees the inclusion of the private logics in public schools as part of changes occurred in this particular period of the capitalism and which redefine the role of the State and social policies. Overall, it was concluded that the public-private relationship comes up during the current period in what refers to the change of ownership and also to what remains as the state ownership, besides reorganizing the educational processes under the logics of the market .

Key words: third way; public/private partnership in education; educational policies; democratic management.

Este artigo trata da relação público/privado e das implicaçóes para a gestão da educação. Destacamos um duplo movimento de mudanças, nessa relação, que redefinem o papel do Estado: o primeiro é a alteração da propriedade, ocorrendo a passagem do estatal para o público não estatal ou privado; já no segundo, permanece a propriedade estatal, mas passa a haver a lógica de mercado, reorganizando, principal-

Programa de Pós-Graduação em Educação (PPGEDU) da Universidade Federal do Rio Grande do Sul (UFRGS), Brasil. veraperoni@gmail.com 
mente, os processos de gestão, o que alguns autores têm chamado de quase-mercado. Neste artigo, enfatizaremos os dois casos, considerando como o público não estatal influencia a gestấo pública por meio de parcerias, destacando o caso do Instituto Ayrton Senna, que foi objeto de uma pesquisa nacional recentemente concluída ${ }^{1}$, e o do Programa do Governo Federal vinculado ao Plano de Desenvolvimento da Educação, o PDE Escola, que é parte de uma pesquisa em andamento ${ }^{2}$.

$\mathrm{O}$ texto contempla o debate acerca das redefiniçôes no papel do Estado. $\mathrm{O}$ pressuposto teórico-metodológico que embasa nossas pesquisas é o de que a política educacional é parte da materialização do Estado, que, por sua vez, é parte do movimento histórico em um período particular ${ }^{3}$ do capitalismo. Portanto, o Estado não é entendido como uma abstração; é construído por sujeitos individuais e coletivos ${ }^{4}$ em um processo histórico de correlação de forças.

Entendemos que as mudanças na gestão são partes de alterações societárias. Em uma sociedade hegemonizada pelo capital, a gestão pública sempre teve como parâmetro o mercado, mas diferentes organizaçóes da produção interferem de diferentes formas na gestão do trabalho e nos parâmetros para o setor público, em particular, para a educação. Outro fator que também consideramos importante para a mudança nos parâmetros da gestáo pública é a proposta de quase-mercado da Public Choice, corrente neoliberal que propóe aproximação cada vez maior entre as escolhas públicas e os parâmetros do mercado.

Entendemos que, no caso brasileiro, há uma especificidade, pois, com o processo de abertura política, após longa ditadura, a luta pela democratização da sociedade passou também pela construçáo de uma gestão democrática da educação. No entanto, ao mesmo tempo que lutávamos muito, na América Latina, para conquistar os nossos direitos, as estratégias do capitalismo para superar suas crises já redefiniam o papel do Estado, com a perda de direitos sociais, materializados em políticas públicas.

\section{Redefinições no papel do Estado e consequências para a democracia}

Partimos da tese, já desenvolvida em trabalhos anteriores ${ }^{5}$, segundo a qual existe uma crise estrutural do capital ${ }^{6}$, e o neoliberalismo, a globalização, a rees-

I Pesquisa nacional "Análise das consequências de parcerias firmadas entre municípios brasileiros e a Fundação Ayrton Senna para a oferta educacional", envolvendo dez grupos regionais, financiada pelo CNPQ (2009-201 I).

2 Pesquisa "Parcerias entre sistemas públicos e instituições do terceiro setor: Brasil, Argentina, Portugal e Inglaterra: implicações para a democratização da educação", financiada pelo CNPq (20|l-20|4).

3 Particular, aqui, na concepção de Lukács (1978).

4 Sujeitos individuais e coletivos, na concepção de Thompson (1981).

5 Ver Peroni $(2003,2006)$ e Adrião, Peroni (2005).

6 Essa afirmação está baseada nos autores: Chesnais (2005), Mészaros (2002) e Brenner (2008). 
truturação produtiva e a Terceira Via são estratégias do capital para superação de sua crise de diminuiçáo na taxa de lucro, o que redefine o papel do Estado. Assim, a crise no Estado seria consequência, e não causa. No entanto, para a teoria neoliberal, o Estado é o culpado pela crise, tanto porque gastou mais do que podia para legitimar-se, pois tinha que atender às demandas da população por políticas sociais, o que provocou déficit fiscal, quanto porque, ao regulamentar a economia, atrapalhou o livre andamento do mercado. Para superar o problema, propóe-se o Estado mínimo, tanto na execução quanto na coordenaçáo da vida em sociedade, e quem passa a ser parâmetro de eficiência e qualidade é o mercado. Isso vai trazer profundas consequências para o que estamos estudando: gestão democrática e parcerias entre o público e o privado (Peroni, 2010).

O neoliberalismo defende claramente o Estado mínimo e a privação de direitos, além de penalizar a democracia, por considerá-la prejudicial aos interesses do mercado. Já a Terceira Via se coloca entre o neoliberalismo e a antiga social-democracia, mas não rompe o diagnóstico de que o Estado é culpado pela crise.

Elaboramos um quadro síntese, mas não no sentido de minimizar as contradiçôes e todas as mediaçóes necessárias na análise das propostas práticas do neoliberalismo e da Terceira Via; ao contrário, a ideia é visualizar alguns pontoschave das suas teorias, para verificar as continuidades e as descontinuidades que elas propóem, e é claro que, nas práticas sociais, há um grande hibridismo entre as propostas nos países.

Quadro I - Pontos principais do neoliberalismo e da

Terceira Via - semelhanças e diferenças

\begin{tabular}{|l|l|l|}
\hline & Neoliberalismo & Terceira Via \\
\hline Estado & mínimo & $\begin{array}{l}\text { Reforma do Estado Administração } \\
\text { gerencial parcerias }\end{array}$ \\
\hline Gestão & gerencial & gerencial \\
\hline Democracia & $\begin{array}{l}\text { Totalitária, culpada pela crise, } \\
\text { Estado gastou demais atendendo } \\
\text { à demanda dos eleitores }\end{array}$ & $\begin{array}{l}\text { Deve ser fortalecida Democratizar a } \\
\text { democracia "participação da sociedade } \\
\text { na execução das políticas" }\end{array}$ \\
\hline Políticas Sociais & Privatização & Parcerias com o terceiro setor \\
\hline Sujeitos & $\begin{array}{l}\text { Individualismo Teoria do capital } \\
\text { humano }\end{array}$ & $\begin{array}{l}\text { Individualismo Teoria do capital } \\
\text { humano }\end{array}$ \\
\hline
\end{tabular}

Elaborado pela autora (Peroni, 20I I, p. 202), com modificações para este texto.

Portanto, o diagnóstico é o mesmo, mas algumas estratégias são diferentes e outras, semelhantes. O neoliberalismo propóe o Estado mínimo, privatizando e 
tendo o mercado como parâmetro para a gestão pública; a Terceira Via propóe reformar o Estado, argumentando que este é ineficiente; assim, a reforma do Estado terá como parâmetro de qualidade o mercado, por intermédio da administração gerencial, fortalecendo a lógica de mercado dentro da administração pública. Dessa maneira, tanto o neoliberalismo quanto a Terceira Via usam a gestão gerencial como parâmetro para a gestáo pública.

Para Hayek (1983), a democracia é totalitária; já Giddens (2001), teórico da Terceira Via, propóe democratizar a democracia, com maior participaçáo da sociedade civil. A sociedade civil a que ele se refere é a empreendedora, que assumirá a execução das políticas sociais:

O empreendedorismo civil é qualidade de uma sociedade civil modernizada. Ele é necessário para que os grupos cívicos produzam estratégias criativas e enérgicas para ajudar na lida com problemas sociais. O governo pode oferecer apoio financeiro ou proporcionar outros recursos a tais iniciativas (Giddens, 2007, p. 26).

Assim, a responsabilidade pela execução das políticas sociais deve ser repassada para a sociedade: para os neoliberais, através da privatização (mercado), e para a Terceira Via, pelo terceiro setor.

$\mathrm{O}$ individualismo é uma posição comum ao neoliberalismo e à Terceira Via. Para esta, cada indivíduo é responsável por abrir o seu caminho, e as transformaçóes ocorrerão na esfera pessoal, e não societária - mesma concepção da teoria do capital humano, que reforça o individualismo e a meritocracia.

Nesse sentido, questionamos o que significam democracia e participação para a Terceira Via, quando a sociedade civil é muito mais chamada a executar tarefas do que a participar nas decisóes e no controle social. A democratização seria apenas para repassar tarefas que deveriam ser do Estado. A sociedade acaba se responsabilizando pela execução das políticas sociais em nome da democracia (Peroni, 2006).

Concordamos com Wood, quando destaca que o conceito de democracia, em uma sociedade sob a hegemonia do capitalismo, náo pode ser visto em abstrato, pois, afinal, "é o capitalismo que torna possível uma forma de democracia em que a igualdade formal de direitos políticos tem efeito mínimo sobre as desigualdades ou sobre as relaçóes de dominação e de exploração em outras esferas" (Wood, 2003, p. 193).

Essa análise de Wood encaminha as discussóes sobre como, neste período particular do capitalismo, por um lado, avançamos na táo batalhada democracia, mas, por outro, há um esvaziamento das políticas sociais, principalmente das políticas sociais como um direito universal. Aumentou, portanto, a separação entre o econômico e o político, historicamente presente no capitalismo. 


\section{O mercado como parâmetro de qualidade: quase-mercado}

Analisamos, no item anterior, que o neoliberalismo e a Terceira Via têm o mesmo diagnóstico de que não é o capitalismo que está em crise, mas o Estado; portanto, o mercado é que deverá superar as suas falhas; assim, a lógica do mercado deve prevalecer, inclusive no Estado, para que ele possa ser mais eficiente e produtivo. Entendemos que esse é o principal motivo pelo qual tanto o neoliberalismo quanto a Terceira Via têm como parâmetro o quase-mercado, termo utilizado pela Public Choice $^{7}$, corrente neoliberal.

A ideia-chave da Public Choice é de que o paradigma da ação humana, em todas as dimensóes, passa pela troca, pelo jogo de interesses. Isso é tanto um pressuposto quanto uma prescrição, no sentido de que a Escola trabalha para que todas as relaçôes tenham a troca como modelo (Buchanan et al., 1984).

Como afirma Reginaldo Moraes (2001), para a Public Choice,

O funcionamento da ordem de mercado é visto como um paradigma, um modelo de funcionamento para outras instituições sociais. Assim, a pretensão destes analistas [neoliberais] é descobrir quais as regras constitucionais que, no plano das decisóes coletivas (não-mercado), mais se aproximam da perfeição exibida por essa ordem (a do mercado) (Moraes, 2001, p. 49).

No caso brasileiro, essa proposta materializou-se através do Plano Diretor da Reforma do Estado, em 1995 (Brasil, 1995). No Plano, as políticas sociais foram consideradas serviços não exclusivos do Estado e, assim sendo, de propriedade pública não estatal ${ }^{8}$ ou privada. Além disso, são consideradas "atividades competitivas e podem ser controladas não apenas através da administraçấo gerencial, mas também e, principalmente, através do controle social e da constituição de quase-mercados" (Bresser Pereira, 1997, p. 8).

Verificamos que tanto o processo de publicização, com a passagem para o público não estatal, principalmente através de parcerias, quanto a proposta de gestão gerencial tiveram continuidade nos governos posteriores?. Isso pode ser verificado, por exemplo, na Carta de Brasília, que apresenta uma proposta de gestáo pactuada pelo Ministério do Planejamento e Secretários Estaduais de Administração (Brasil, 2009) com os princípios da gestão gerencial e no Plano de Gestão do Governo

$7 \quad$ O seu principal teórico é James Buchanan; é também conhecida como Escola de Virgínia, pois se constituiu no Instituto Politécnico da Universidade de Virgínia na década de 1950.

8 Com o público não estatal, a propriedade é redefinida, deixa de ser estatal e passa a ser pública de direito privado.

9 Luis Inácio Lula da Silva (2003-20 I 0) e Dilma Roussef (20 I I-20 I 4).

Pro-Posiçóes, Campinas, v. 23, n. 2 (68), p. 19-31, maio/ago. 2012 
Lula, "Gestão pública para um país de todos", do Ministério do Planejamento, Orçamento e Gestão (Brasil, 2003).

Essa concepção de gestão que tem princípios no quase-mercado está sendo aprofundada pelo governo Dilma Rousseff, com a criação, em maio de 2011, da Câmara de Políticas de Gestão, Desempenho e Competitividade (CGDC), presidida por Jorge Gerdau, empresário brasileiro que vem fazendo uma verdadeira cruzada para que a lógica de mercado seja incorporada na gestão pública ${ }^{10}$.

\section{Gestão da educação}

Historicamente, o mercado foi o padrão para o público. Os princípios da administração científica de Taylor tinham o objetivo de acelerar o processo produtivo, produzindo mais em menos tempo e com qualidade, por meio, entre outros, da divisão do trabalho; da especialização; do controle pela gerência; da padronização, com aplicação de métodos científicos para obter a uniformidade e reduzir custos; e de incentivos salariais e prêmios por produtividade.

É o que vemos hoje com os "métodos replicáveis" de apostilas no ensino superior ou na venda de sistemas de ensino, ou em parcerias que vendem um pacote pronto. Assim, verificamos que muitos dos elementos propostos por Taylor estão bem presentes nas propostas atuais de gestão de mercado para o público, apesar de o discurso ser de modernização na gestão.

Porém, as teorias de administração gerencial não são apenas discursos; também influenciam a gestão da educação. Assim como o neoliberalismo e a Terceira Via trouxeram influências do quase-mercado para a administração pública, outra estratégia do capital para superação da sua crise que acarretou importantes mudanças foi a reestruturação produtiva, com os princípios de flexibilização, trabalho em equipe, compressão espaço-tempo e respostas rápidas e criativas às demandas.

Entendemos que há um hibridismo nas concepçôes e nas práticas vivenciadas pelas escolas, misturando desde os princípios do patrimonialismo e do clientelismo até a administração burocrática e a gestão gerencial.

10 A Câmara contará com quatro representantes da sociedade civil, "com reconhecida experiência e liderança nas áreas de gestão e competitividade", segundo a Presidência da República: o empresário Jorge Gerdau Johannpeter (presidente do Conselho de Administração do Grupo Gerdau), que presidirá a Câmara de Políticas de Gestão; Abílio Diniz (dono da Companhia Brasileira de Distribuição - redes Pão de Açúcar, Extra, Compre Bem, Sendas e Ponto Frio); Antônio Maciel Neto (presidente da Suzano Papel e Celulose); e Henri Philippe Reichstul (expresidente da Petrobrás - 1999/200 I). Pelo governo federal, participam os ministros da Casa Civil, da Fazenda, do Planejamento e do Desenvolvimento, Indústria e Comércio Exterior. (http:// economia.estadao.com.br/noticias, acesso em 12 de maio de 201 I). 


\section{Consequências para a gestão democrática}

O conceito de democracia trabalhado neste artigo é o de que ela deve ser entendida como a não separação entre o econômico e o político, e como a materialização de direitos e igualdade social. Reivindicamos direitos sociais universais - a questão é quem tem o dever de assegurá-los. Entendemos que o poder público tem esse dever, mas, para o neoliberalismo e a Terceira Via, o Estado não deve mais ser o executor, repassando as políticas sociais ou para o setor privado ou para o terceiro setor; desse modo, acabam-se retirando os direitos já conquistados ou em processos de materialização.

No Brasil, assim como em outros países da América Latina, ocorreu um enorme descompasso entre o processo de abertura democrática e as estratégias do capital para superação da crise, que já estavam em curso e minimizavam os direitos sociais, como já mencionamos no item anterior.

Os anos 1980 foram marcados por um processo de abertura política, com participação popular e organização da sociedade na luta por direitos, gestáo democrática do Estado, enfim, a construção de uma sociedade mais justa e igualitária. Esses movimentos foram frustrados, em parte, pelos pactos feitos pelo alto, em que o mesmo grupo dirigente continuou no poder; e, em parte, pelas estratégias do capital de minimização de direitos.

Apesar de termos avançado na materialização de direitos por meio da legislação, temos a dificuldade de implementá-los, não só pela ofensiva neoliberal, mas também porque a nossa cultura democrática é ainda muito embrionária. Isso facilita o consenso em torno da lógica de mercado e de produto, em detrimento da lógica democrática, com ênfase na participação coletiva das decisóes e no processo.

A luta pela democratização da sociedade também era parte do processo de democratização da educação. Nesse sentido, a gestão democrática é um fim, e não apenas um meio, já que não é simplesmente uma mudança na concepção de gestão, que passaria da tecnocrática, vinculada aos preceitos do Fordismo e Toyotismo, para a gestão democrática.

Concordamos com a concepção de gestão democrática apresentada por Cury (2007):

A gestão democrática da educação é, ao mesmo tempo, por injunção da nossa Constituição (art. 37) (Brasil, 1988): transparência e impessoalidade, autonomia e participação, liderança e trabalho coletivo, representatividade e competência. Voltada para um processo de decisão baseado na participação e na deliberação pública, a gestão democrática expressa um anseio de crescimento dos indivíduos como cidadãos e do crescimento da sociedade enquanto sociedade democrática (Cury, 2007, p. 12). 
A gestão democrática é parte do projeto de construção da democratização da sociedade brasileira. Nesse sentido, a construção do projeto político-pedagógico, a participação em conselhos, a eleição para diretores, a autonomia financeira, são processos pedagógicos de aprendizagem da democracia, tanto para a comunidade escolar, quanto para a comunidade em geral, porque a participação, depois de muitos e muitos anos de ditadura, é um longo processo de construçáo.

\section{Público/privado e a gestão democrática}

Historicamente, foram muito tênues as linhas divisórias entre o público e o privado no nosso país. Não é um processo novo, que ocorre simplesmente pelos princípios neoliberais da Public Choice ou pela reestruturação produtiva, que requer sujeitos com competências específicas para as novas demandas do mercado. Como mencionamos no início do artigo, o Estado, a gestão pública e, em especial, a educacional materializam-se em um determinado momento histórico com características específicas e são parte de um movimento histórico maior. Nesse sentido, verificamos que, no Brasil, a concepção de quase-mercado na educaçáo tem sido introduzida principalmente pela interlocução direta dos empresários com os governos, como no movimento Todos pela Educação, ou por parcerias em todos os níveis, desde o nacional até o escolar, como, por exemplo, com o Instituto Ayrton Senna ou o Instituto Unibanco, com o Programa Jovem do Futuro - enfim, inúmeras entidades privadas, que têm o mercado como parâmetro de qualidade e a simpatia da sociedade, por se apresentarem como instituiçôes filantrópicas, sem fins lucrativos, que querem o "bem" da educação.

Temos uma trajetória de estudos sobre as redefiniçóes do papel do Estado e, nos últimos anos, mais especificamente, sobre as mudanças nas fronteiras entre o público e o privado, tanto no que se refere à mudança de propriedade, quanto ao que continua como propriedade estatal, mas passa a ter a lógica de mercado.

Analisamos a relação público/privado em um grupo nacional, que iniciou com a participação de cinco grupos estaduais, na pesquisa "O Programa Dinheiro Direto na Escola: uma redefinição do papel do Estado na educação" 11 (Peroni; Adrião, 2007). O objetivo era analisar o Programa Dinheiro Direto na Escola, que instituiu a obrigatoriedade, para o recebimento dos recursos, da criação de Unidades Executoras de direito privado nas escolas públicas. Verificamos que o "fluxo" do dinheiro, que é público, passa por uma instituição privada (Unidade Executora), para ser gasto pelo poder público - isso parece estar de acordo com o diagnóstico neoliberal de que o privado é mais eficiente.

I I Financiada pelo Edital Universal/CNPq. 
O grupo nacional foi expandido e passou para dez grupos regionais, com a pesquisa "Análise das consequências de parcerias firmadas entre municípios brasileiros e a Fundação Ayrton Senna para a oferta educacional" ${ }^{12}$. Escolhemos o Instituto Ayrton Senna (IAS) pela importância de sua atuação nas redes públicas de ensino em todo o País.

Verificamos na pesquisa que, entre as principais implicaçóes da parceria para a gestão democrática da educação, está a diminuição da autonomia do professor, que recebe o material pronto para utilizar em cada dia na sala de aula e conta com um supervisor para verificar se está tudo certo. Há, ainda, a lógica da premiação por desempenho, que estabelece valores, como o da competitividade entre alunos, professores e escolas, como se a premiaçấo dos mais capazes induzisse à qualidade, via competição.

Outra questão diz respeito às metas estabelecidas, que passam a dar mais ênfase ao produto final, e não mais ao processo, como é característica da gestão democrática, que visa a construir uma sociedade democrática e participativa.

Continuamos analisando as relaçóes entre o público e o privado com a pesquisa "Parcerias entre sistemas públicos e instituições do terceiro setor: Brasil, Argentina, Portugal e Inglaterra: implicaçôes para a democratização da educação" ${ }^{13}$, que objetiva estudar a relação entre o público e o privado, pela análise das parcerias entre sistemas públicos e instituiçóes do terceiro setor, e as consequências para a democratização da educação no Brasil, na Argentina, na Inglaterra e em Portugal. Queremos entender como países com trajetórias distintas, em termos de papel do Estado, na consecução do direito à educação, vivenciam este período particular do capitalismo, com as consequentes mudanças na relação entre o público e o privado e a intervenção da lógica do privado na educação pública.

Para dialogar com os outros países, analisamos ${ }^{14}$ as políticas educacionais que envolvem a relação público/privado na educação básica no Brasil, em todas as etapas (Educação Infantil, Ensino Fundamental e Médio) e modalidades (Educação de Jovens e Adultos, Educação Especial e Educação Profissional), assim como a proposta de gestâo pública do governo federal.

No Ensino Fundamental, estudamos algumas parcerias e o PDE/Plano de Metas/PAR (Plano de Açóes Articuladas), do governo federal. No PAR, já é possível verificar o processo de indução das parcerias por meio das tecnologias sociais certificadas e, até mesmo, financiadas pelo governo federal. Verificamos também as formas de indução de parcerias via PAR e destacamos que, por esse programa, a política de parcerias chega a todos os municípios e escolas no Brasil.

I2 Pesquisa coordenada pela professora Theresa Adrião, com vice-coordenação de Vera Peroni, e parcialmente financiada pelo edital Ciências Humanas/CNPq.

13 Bolsa Produtividade CNPq (20 | |-20 |4)

14 Grupo de pesquisa vinculado ao PPGEDU/UFRGS e ao núcleo de Políticas e Gestão da Educação. 
Como o assunto deste artigo é a gestão, destacamos o PDE Escola, que é uma continuidade do Programa Fundescola, financiado pelo Banco Mundial e expandido para todas as regióes brasileiras. Neste momento, entra em todas as escolas pelo Programa Federal Plano de Desenvolvimento da Escola (PDE Escola), vinculado ao Plano de Desenvolvimento da Educação, na dimensão da gestão educacional do Plano de Açóes Articuladas (PAR).

Antes de ser expandido para todas as regiôes, o PDE já era muito criticado; inclusive, uma pesquisa vinculada à Associação Nacional de Política e Administração da Educação (Anpae) já apontava para a proposta de gestão do PDE em dissonância com a gestấo democrática:

A investigação analisa, mediante abordagem qualitativa, o impacto dessas experiências na gestão e na organização de escolas básicas brasileiras. Percebe o fortalecimento de uma visão gerencial "estratégica", centrada na racionalização de gastos e na eficiência operacional. Percebe, ainda, uma divisão do trabalho escolar que se aproxima da racionalidade taylorista, separando quem decide de quem executa, além de fragmentar as açóes em projetos desprovidos de sentido político (Fonseca, 2003, p. 1, autoria do grifo).

É impressionante verificar que, após tantos questionamentos da área, o Programa foi expandido para todas as regiōes, entrando em todas as escolas brasileiras quase sem resistência, o que terá um impacto enorme para a gestão democrática.

Conforme Lumertz (2011), o PDE-Escola é dividido em cinco etapas. A primeira é a preparação, em que a escola se organiza para o processo de elaboração do PDE-Escola. A segunda etapa é a análise situacional, que prevê a coleta de dados da escola e a análise destes conforme os critérios de eficácia: Ensino e Aprendizagem, Clima Escolar, Pais e Comunidade, Gestão de Pessoas, Gestão de Processos, Infraestrutura e Resultados. A terceira etapa é o Plano de Suporte Estratégico, composto pelos objetivos estratégicos, pelas estratégias, pelas metas e pelos planos de ação que darăo suporte para a transformação dos objetivos da escola. A quarta etapa é a execução, quando as definiçôes da escola serão colocadas em prática, envolvendo o comitê estratégico, o coordenador do PDE, líderes de objetivos, gerentes dos Planos de Ação e equipes dos Planos de Ação. A quinta etapa é o monitoramento e a avaliação, que consiste em reunióes com todos os envolvidos e preenchimento de planilhas para acompanhamento dos Planos de Ação.

As etapas de um a três resultarão num documento com o levantamento dos dados das escolas e as açóes que elas priorizaram. Para custear essas açóes, é disponibilizado o financiamento para as Escolas Prioritárias e para as escolas que tiveram um Ideb muito baixo. Os planos de açóes foram construídos pelas escolas, tendo 
previsão de dois anos. Depois de finalizadas as etapas de um a três, a primeira parte do financiamento foi disponibilizado na conta das escolas, via unidade executora. No segundo ano, as escolas teriam direito a receber a segunda parte do recurso.

Ao elencar as fases do processo, já é possível perceber alguns conceitos que embasam a proposta de gestão, como, por exemplo, gerentes, líderes e metas, entre outros.

É interessante que o Plano de Açóes Articuladas (PAR), ao mesmo tempo que desenvolve o PDE-Escola orientado por uma gestáo de natureza gerencial, também oferece a Escola de Gestores, um curso de especialização para diretores de escolas públicas que tem toda a sua proposta curricular e seu formato no sentido de fortalecer a gestáo democrática da educação.

\section{Considerações finais}

Reivindicamos direitos sociais universais, mas a questão é quem tem o dever de assegurá-los. Entendemos que o poder público tem esse dever, mas estão em jogo tanto a execução da política quanto o seu conteúdo. A democratização do Estado e da sociedade é um processo longo e difícil e passa pela educação em todos os níveis e instâncias. Assim, quando abrimos mão da gestão democrática pela lógica gerencial, que quer um produto rápido e adequado às exigências do mercado no período atual, estamos pactuando com outra proposta de educaçáo e sociedade e desistindo ou minimizando a importância da construçáo da democracia que historicamente não tivemos.

Enfim, são muitas as questôes e, principalmente, as consequências para a gestáo e para a democratização da educaçáo neste período histórico. Vivemos num período democrático, mas está naturalizada a ideia de que não é mais possível a universalização de direitos sociais e também de que o parâmetro de qualidade está no mercado. Por fim, destacamos que a democracia não é uma abstração e deve ser entendida como a não separação entre o econômico e o político, como a materialização de direitos e igualdade social.

\section{Referências bibliográficas}

ADRIÃO, T.; PERONI, V. (Org.). O público e o privado na educação: interfaces entre estado e sociedade. São Paulo: Xamá, 2005.

BRASIL. Ministério da Administração e Reforma do Estado (MARE). Plano Diretor da Reforma do Aparelho de Estado. Brasília, 1995.

BRASIL. Ministério do Planejamento, Orçamento e Gestâo. Plano de Gestão do Governo Lula. Brasília, DF, 2003. 
BRASIL. Ministério do Planejamento, Orçamento e Gestão. Carta de Brasília. Brasília, DF, 2009.

BRENNER, R. O princípio de uma crise devastadora. Virus - Portal Esquerda.net, Portugal, n. 3, jun./jul. 2008. Disponível em: < http://www.esquerda.net/virus/media/virus3.pdf >.

BRESSER PEREIRA, L. C. A reforma do Estado dos anos 90 crise e reforma. Disponível em: <http://www.mare.gov.br/reforma>. Acesso em: 3 jun. 1997.

BUCHANAN, J.; MCCORMICK, R.; TOLLISON, R. El analisis economico de lo politico: lecturas sobre la teoria de la elección publica. Madrid: Instituto de Estudios Economicos, 1984.

CHESNAIS, F. (Org.) A finança mundializada. São Paulo: Boitempo, 2005.

CURY, C. J. A gestão democrática na escola e o direito à educação. Revista Brasileira de Política e Administração da Educação, v. 23, n. 3, p. 483-495, set./dez. 2007.

FONSECA, M. Projeto político pedagógico e o Plano de Desenvolvimento da Escola: duas concepçóes antagônicas de gestão escolar. Cadernos CEDES, v. 23, n. 61, p. 302-318, 2003. [online].

GIDDENS, A. A Terceira Via: reflexóes sobre o impasse político atual e o futuro da socialdemocracia. Rio de Janeiro: Record, 2001.

GIDDENS, A. (Org.). O debate global sobre a Terceira Via. São Paulo: Editora Unesp, 2007.

HAYEK, F. O caminho da servidão. Rio de Janeiro: Livraria O Globo, 1983.

LUKÁCS, G. Introdução a uma estética marxista. Rio de Janeiro: Civilização Brasileira, 1978.

MÉSZAROS, I. Para além do Capital. São Paulo: Boitempo; Campinas: Editora da Unicamp, 2002.

MORAES, R. Neoliberalismo: de onde vem, para onde vai? Sáo Paulo: Senac Editora, 2001. (Série ponto futuro, v. 6).

PERONI, V. M. V. Política educacional e papel do Estado no Brasil dos anos 90. São Paulo: Xamã, 2003.

PERONI, V. M. V. Mudanças na configuração do Estado e sua influência na política educacional. In: PERONI, V. M. V.; BAZZO, V. L.; PEGORARO, L. (Org.). Dilemas da educação brasileira em tempos de globalização neoliberal: entre o público e o privado. Porto Alegre: Editora da UFRGS, 2006.

PERONI, V. M. V. A democratização da educação em tempos de parcerias entre o público e o privado. Revista de Educação Pública - UFMT, v. 19, p. 215-227, 2010.

PERONI, V. M. V. Privatização do público versus democratização da gestão da educação. In: GOUVEIA, A.; PINTO, M.; CARBUCCI, P. Federalismo e politicas na efetivação do direito à educação no Brasil. Brasília: IPEA, 2011.

PERONI, V.; ADRIÃO, T. Programa Dinheiro Direto na Escola: uma proposta de redefinição do papel do Estado na educação? Brasília: INEP, 2007. 
THOMPSON, E. P. A miséria da teoria ou um planetário de erros. Uma crítica ao pensamento de Althusser. Rio de Janeiro: Zahar, 1981.

WOOD, E. M. Democracia contra o capitalismo a renovação do materialismo histórico. São Paulo: Boitempo, 2003.

Recebido em 05 de janeiro de 2012 e aprovado em 06 de março de 2012. 
